\title{
Impact of admixtures used in underwater concrete on cement hydration process and rheological properties
}

\author{
Aneta Matuszek-Chmurowska ${ }^{1,{ }^{*}}$, Alina Kaleta-Jurowska ${ }^{1}$, Krystian Jurowski ${ }^{1}$, \\ and Stefania Grzeszczyk ${ }^{1}$ \\ ${ }^{1}$ Opole University of Technology, Faculty of Civil Engineering and Architecture, Department of \\ Building Materials Engineering, 45-061 Opole, Poland
}

\begin{abstract}
This paper presents test results of the impact of chemical admixtures used in the underwater concrete technology, i.e. a superplasticizer (SP), an anti-wash admixture (AWA) and $\mathrm{SiO}_{2}$ nanoparticles (NP) on the cement hydration process, rheological properties and the setting time. The impact of admixtures was tested in combination and separately, with the use of microcalimetry, X-ray diffraction (XRD) and rheology. It was demonstrated that AWA and SP admixtures caused a delay of the hydration process, while the impact of SP was much greater. The above statement was also confirmed by results of rheological tests. Combined application of AWA, SP and NP causes even a larger delay of the hydration process and the increase of paste rheological parameters, with the impact of the superplasticizer particularly visible.
\end{abstract}

\section{Introduction}

During underwater concrete work, properties of the concrete mix are very important. Its composition has to ensure suitable rheological properties, as well as the lowest washout tendency [1]. Reduction of water amount in a concrete mix, while keeping the resistance of the cement paste to washout, requires simultaneous application of both the superplasticizer and anti-washout admixture (AWA) [2]. Suitable water reduction of underwater concretes recently installed is reached by application of a new-generation polycarboxylate-based superplasticizers.

Whereas applied viscosity enhancing chemical admixtures form a very wide group of polymers. According to Kawai [3], they are natural polymers that include starch, natural gum and plant protein. Next ones are semi-synthetic polymers containing decomposed starch and its derivatives, cellulose-ether derivatives, as well as synthetic polymers based on ethylene and vinyl. To viscosity enhancing admixtures, Ramachandran [4] also classifies high surface area inorganic materials that swell in water, as well as materials that increase the content of fine particles in pastes. They are fly ash, hydrated lime, diatomaceous earth. It is generally assumed that action of AWA consists in "cross-linking" of binder grains by long chains of

*Corresponding author: a.matuszek-chmurowska@po.edu.pl 
polymers. Chains of polymers interlace fine particles of the cement, which in consequence increases the paste viscosity, which grows along with the increase of the admixture content [5].

The flowability and washout resistance of underwater concrete mixes depend mainly on the addition of AWA and SP [2], but, as proved by tests of the concrete washout resistance, they also strongly depend on the content of dust fractions in the binder. A particularly favourable impact on the washout properties is observed in case of silica fumes [6-7], limestone powder [8], blast furnace slag and fly ashes [1], as well as a small amount of nanoparticles added to the cement [9]. Both chemical admixtures and mineral additives to the cement used in the underwater concrete technology have the impact on the cement hydration process and the rheological properties of concrete mix.

The influence of polycarboxylate-based superplasticizers on the delay of the cement hydration process is well-known [10]. Due to a wide variety of viscosity enhancing admixtures, their impact on the cement hydration process is less known. AWA is generally considered as a factor that delays the cement hydration process in the initial period. It is mainly due to formation of a dense network of AWA polymer chains that hinder migration of water particles and other fine particles [9]. According to authors of the paper [11], AWA may disturb dissolution of cement anhydrous phases, nucleation of hydrates and their growth. A feature common for both admixtures used, i.e. SP and AWA, for underwater concrete, is a presence of long polyoxyethylene chains in their structure, which decide of their mutual compatibility.

The paper presents results of testing of the impact of admixtures used in the underwater concrete technology, i.e. AWA and SP on the cement hydration process and rheological properties of cement pastes. Apart from AWA and SP admixtures, the admixture of $\mathrm{SiO}_{2}$ nanoparticles was also used in testing.

\section{Material for Testing}

Material used for testing was CEM I 42.5 R (CEM I), as well as the following admixtures: polycarboxylate superplasticizer (SP) based on polycarboxylic ester polyethylene oxides, as well as an anti-washout admixture (AWA) based on polyoxyethylene ethers of methylcellulose. Admixture of nano-silica (NP) was also used. A chemical structure of admixtures used is described in the paper [9]. Chemical composition of CEM I cement is presented in Table 1.

Table 1. Chemical composition of CEM I $42.5 \mathrm{R}$

\begin{tabular}{|l|c|c|c|c|c|c|c|c|}
\hline Components & $\mathbf{S i O}_{2}$ & $\mathrm{Al}_{2} \mathrm{O}_{3}$ & $\mathrm{Fe}_{2} \mathrm{O}_{3}$ & $\mathbf{C a O}$ & $\mathbf{M g O}$ & $\mathrm{K}_{2} \mathbf{O}$ & $\mathrm{Na}_{2} \mathbf{O}$ & $\mathbf{S O}_{3}$ \\
\hline CEM I 42.5 R & 19.52 & 6.23 & 2.79 & 62.75 & 1.37 & 0.83 & 0.72 & 2.58 \\
\hline
\end{tabular}

Testing of admixtures impact on hydration process was conducted for each admixture separately and a joint effect of admixtures action was tested. The impact of AWA was tested in quantity: $0.75 \%, 1.5 \%, 2.0 \%, \mathrm{SP}$ in quantity $1.0 \%$ and $2.0 \%, \mathrm{NP}$ in quantity $0.5 \%$ and $1.0 \%$, to the cement weight. A particular attention was paid to properties of the cement paste, contains $0.75 \%$ AWA, $2.0 \%$ SP and $0.5 \%$ NP. For that composition of admixtures, the highest underwater concrete washout resistance was achieved [9]. A water-cement ratio used in testing was as follows: $w / c=0.40$ for pastes without SP and w/c $=0.27$ with SP. 


\section{Testing Methods}

Hydration heat of binders was tested by means of an isothermal micro-calorimeter C-80 manufactured by SETARAM company. The identical procedure of sample preparation for testing, as well as the same testing conditions were maintained for cement pastes tested (test temperature $\left.(21 \pm 1)^{\circ} \mathrm{C}\right)$. Test results were presented in a form of a graph of a heat evolution rate and total heat value.

XRD tests were conducted by means of Philips X'PertSystem diffractometer. The measurement was conducted for $2 \Theta$ within a range from $5^{\circ}$ to $60^{\circ}$. CuK $\alpha$ radiation was used.

Rheological measurements of cement pastes were conducted with the use of HAAKE MARS III rotational viscometer with coaxial cylinders. Tests were performed in a constant ambient temperature $(20.0 \pm 0.2)^{\circ} \mathrm{C}$. The identical procedure of sample preparation for measurement and the same conditions of measurement were maintained [14]. 10 minutes after the binder had been added to water, rheological tests started. A shear rate was increased and then reduced within a range from 0 to $150 \mathrm{~s}^{-1}$, during 6 minutes. Results of tests were presented in a form of flow curves, after 10, 30 and 60 minutes. The yield stress and plastic viscosity values were calculated with the use of Bingham model.

The standard consistency, water demand, as well as initial and final setting time of binders, were determined in accordance with PN-EN 196-3 + A1:2011 standard - Methods of testing cement. Part 3: Determination of setting times and soundness.

\section{Results and discussion}

\subsection{Microcalorimetry and X-ray Diffraction (XRD)}

At the beginning, results of hydration heat tests are presented for CEM I with and without chemical admixtures applied separately in different quantities: AWA - Fig. 1 and SP - Fig. 2. Fig. 3 shows heat evolution rates and total heat values for AWA and SP applied jointly. Also addition of a small amount of NP, applied in practice in order to enhance the effect of the AWA admixture action, was taken into account [9]. The total heat values after 5, 10, 24 and 48 hours are presented in Table 2.

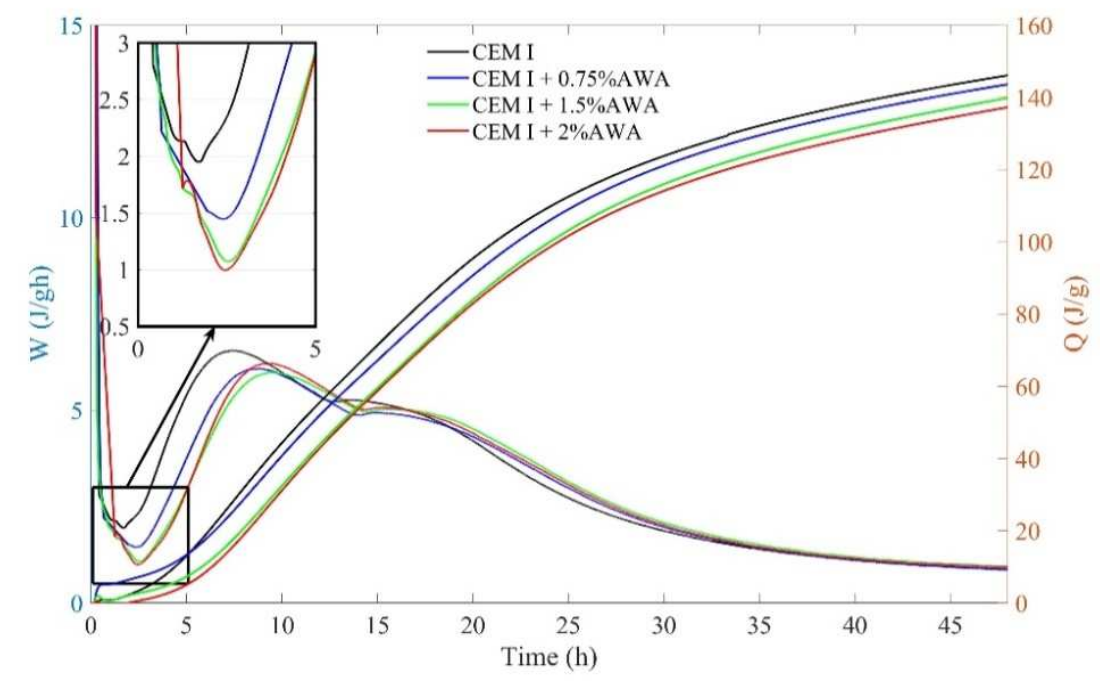

Fig. 1. AWA impact on the heat evolution rate and total hydration heat of cement. 


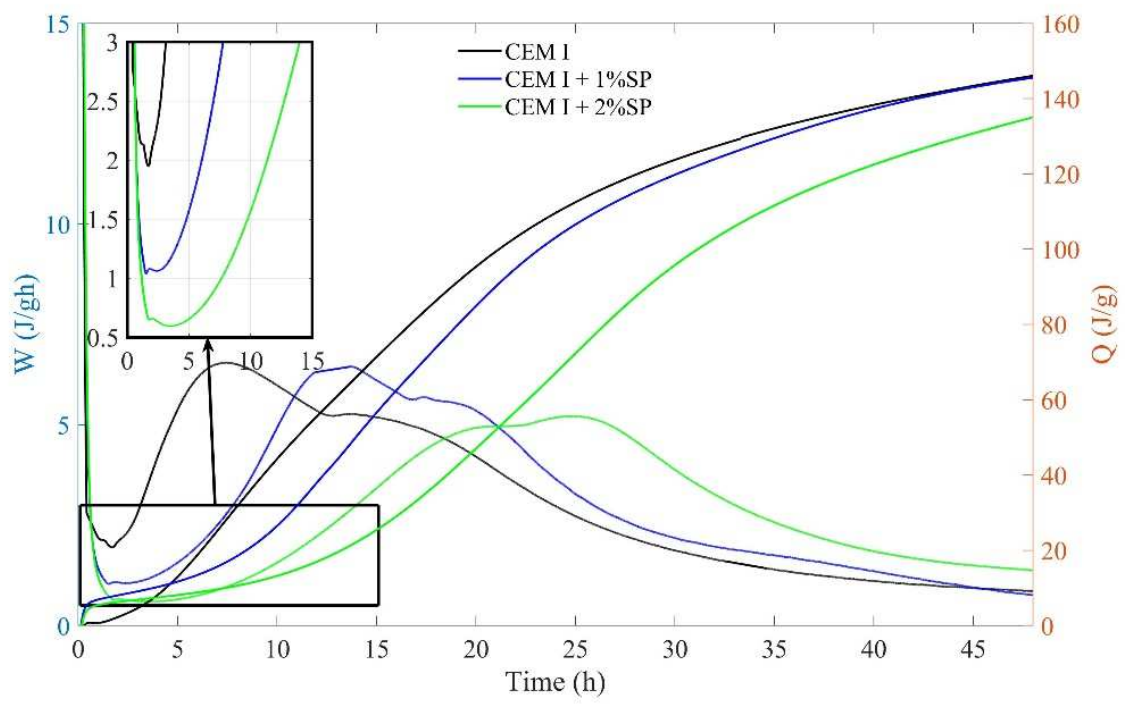

Fig. 2. SP impact on the heat evolution rate and total hydration heat of cement.

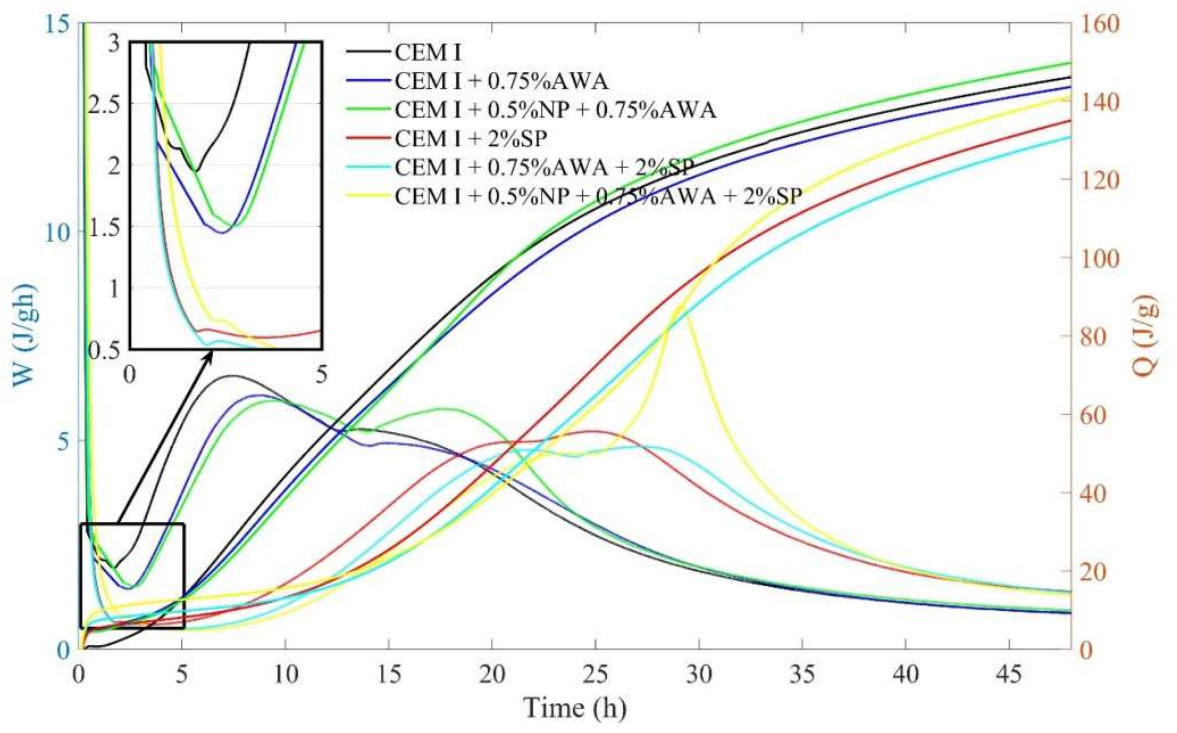

Fig. 3. Impact of AWA, SP and NP admixtures applied separately and jointly on the heat evolution rate and total hydration heat of cement.

Data in Fig. 1 show that AWA causes a delay of cement hydration process, which is the higher, the more admixture is added. It is revealed by extension of the induction time and a shift of maximums of heat evolution effects towards the longer time. On a scaled up fragment of the hydratation heat evolution rate of cements with AWA addition, presented in Figure 1, a clear elongation of the induction period is visible compared to the cement without the admixture. For a specimen with $0.75 \%$ AWA, the induction period is longer by about 40 minutes and by the next 20 minutes on average along with the increase of that admixture quantity. Based on data shown in Table 2 it can be stated that along with the increase of AWA 
quantity, the total cement hydration heat is reduced compared to the cement without the admixture.

Table 2. Total hydration heat after different time $(\mathrm{J} / \mathrm{g})$.

\begin{tabular}{|l|c|c|c|c|}
\hline \multirow{2}{*}{ Sample } & \multicolumn{4}{|c|}{ Total hydration heat after } \\
\cline { 2 - 5 } & $\mathbf{5} \mathbf{~}$ & $\mathbf{1 0 ~ h}$ & $\mathbf{2 4} \mathbf{~ h}$ & $\mathbf{4 8 ~ h}$ \\
\hline CEM I & 13.0 & 44.3 & 109.6 & 146.5 \\
\hline CEM I + 0.75\% AWA & 13.3 & 40.7 & 105.8 & 143.6 \\
\hline CEM I + 1.5\% AWA & 7.3 & 32.4 & 99.9 & 139.8 \\
\hline CEM I + 2\% AWA & 5.0 & 31.1 & 98.4 & 137.2 \\
\hline CEM I + 1\% SP & 11.7 & 26.5 & 103.1 & 145.6 \\
\hline CEM I + 2\% SP & 6.4 & 11.4 & 67.1 & 133.2 \\
\hline CEM I + 0.5\% NP + 0.75\% AWA & 12.5 & 38.5 & 111.2 & 149.7 \\
\hline CEM I + 0.5\% NP + 0.75\% AWA + 2\% SP & 12.7 & 15.6 & 57.6 & 141.1 \\
\hline
\end{tabular}

Results of microcalorimetric tests indicating the reduction of the cement hydration rate under the impact of AWA, were confirmed by results of testing performed by the authors of the paper [14]. Based on results of X-ray diffraction and infrared spectroscopy tests, they found that the quantity of a calcium hydroxide formed during the initial hydration period of the cement was reduced under the influence of various types of AWAs. The delay of the cement hydration process caused by AWA may be explained by its mechanism of action consisting in hindering of water migration to cement grains [5].

As it could be expected, test results of hydration heat of the cement with the polycarboxylate-based superplasticizer addition demonstrated that the increase of that admixture quantity caused the delay of the cement hydration process (Fig. 2). The induction time extends even by ca. 10 hours compared to the cement without the admixture, and thermal effects observed on the heat evolution rate curves shift to the time longer by ca. 17 hours with the addition of $2.0 \%$ SP. A clear extension of the induction period under the influence of polycarboxylate superplasticizers was also found by the authors of papers [15-16]. The delay of the cement hydration process under the SP impact is also reflected in the reduction of the total hydration heat values (Table 2).

Comparison of AWA and SP impact on cement hydration heat (Fig. 1 and 2, Table 2) indicates that SP's impact on the delay of hydration process is much larger than AWA's. It is revealed by a longer induction time, a larger shift of heat effects on the heat evolution rate curve towards the longer time, as well as the lower amount of the total heat evolved during hydration.

Fig. 3 shows curves of heat evolution rates and the total hydration heat for the cement with AWA and SP applied jointly and separately. When AWA was applied together with SP, a slight extension of the induction period was observed and a slight shift of heat effects towards the longer time on the heat evolution rate curves compared to the specimen with SP only. Addition of NP to that arrangement causes further extension of the induction period and the shift of heat effects towards the longer time. Such a phenomenon may be caused by AWA's mechanism of action. $\mathrm{SiO}_{2}$ particles, due to their size, can get located in a dense 
network of developing AWA's polymer chains formed, which hinders migration of water and cement grains in this arrangement even more, and in result it leads to reduction of the cement hydration rate in the initial period of the cement hydration. Test results of the total hydration heat evolved during 48 hours demonstrated that the impact of AWA, SP and NP admixtures on reduction of the cement hydration rate was revealed to the most extent during the initial stage of hydration (Table 2). The amount of heat evolution after 5 hours and 10 hours of hydration of cements with addition of these admixtures is clearly lower compared to the amount of heat evolution in the cement without admixtures. In the later time (48 hours), differences in the total heat evolution are significantly reduced. The amount of CEM I hydration heat evolved is 146.5 , whereas in case of the cement with admixtures mentioned it is $141.1 \mathrm{~J} / \mathrm{g}$.

Tests of cement specimens without and with $0.75 \%$ AWA, as well as $0.75 \%$ AWA and $0.5 \% \mathrm{NP}$, after one day of hydration with the use of X-ray diffraction (XRD) are shown in Fig. 4.

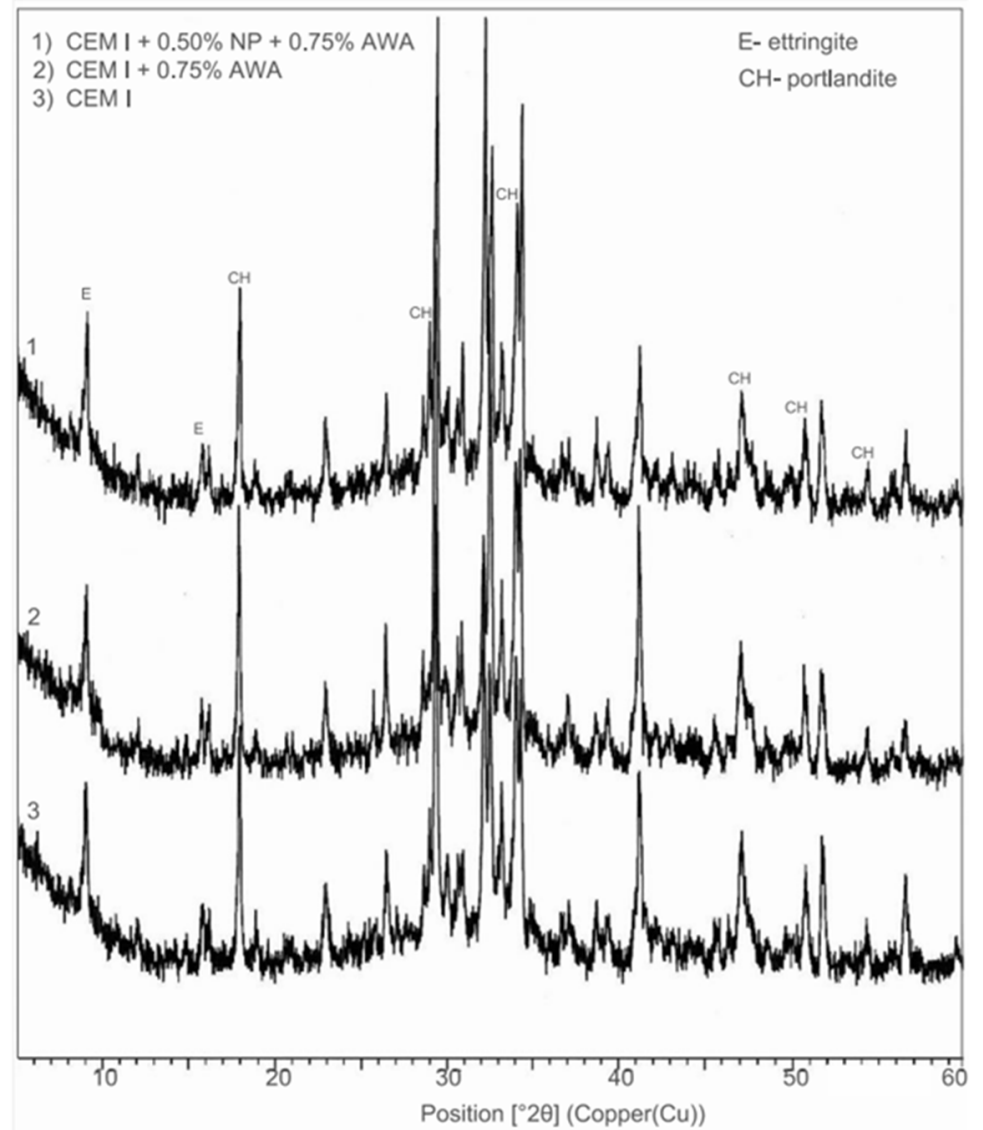

Fig. 4. XRD patterns of CEM I $42.5 \mathrm{R}+0.5 \% \mathrm{NP}+0.75 \%$ AWA (1), CEM I $42.5 \mathrm{R}+0.75 \%$ AWA (2) and CEM I $42.5 \mathrm{R}(3)$.

Based on evaluation of intensity of diffraction lines belonging to hydrated phases, a calcium hydroxide $(\mathrm{CH})$ and an ettringite $(\mathrm{E})$ in diffraction patterns of specimens, it can be stated that they are more or less the same. It means that there are no significant differences in the quantity of these phases in specimens tested after 1 day of hydration. As results of micro-calorimetric testing showed (Table 2), the total heat value after one day of hydration 
of specimens tested did not show the significant differences either; for the cement without the admixture (CEM I) it was 109.6 J/g, for CEM I + 0.75\% AWA - 105.8 J/g and for CEM $\mathrm{I}+0.5 \% \mathrm{NP}+0.75 \%$ AWA $-111.2 \mathrm{~J} / \mathrm{g}$. Results of those tests allow to state that after one day of hydration no impact of AWA on reduction of the cement hydration rate is observed.

\subsection{Rheology}

Flow curves of cement pastes tested are presented in Figures 5-9, and calculated values of the yield stress and plastic viscosity are presented in Figures 10 and 11.

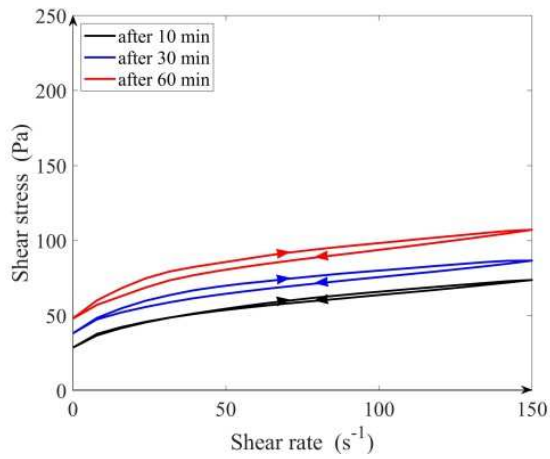

Fig. 5. Flow curves of cement paste CEM I, w/c=0.4.

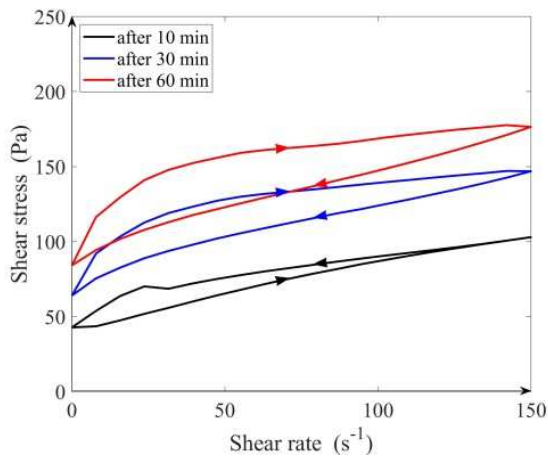

Fig. 7. Flow curves of cement paste $\mathrm{CEM} \mathrm{I}+0.5 \% \mathrm{NP}, \mathrm{w} / \mathrm{c}=0.4$.

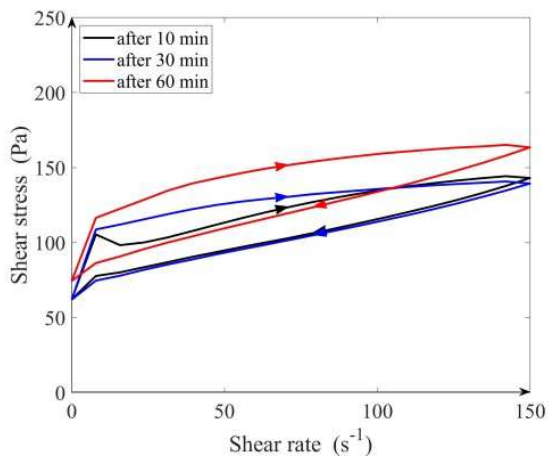

Fig. 6. Flow curves of cement paste CEM I $+0.75 \%$ AWA, w/c $=0.4$.

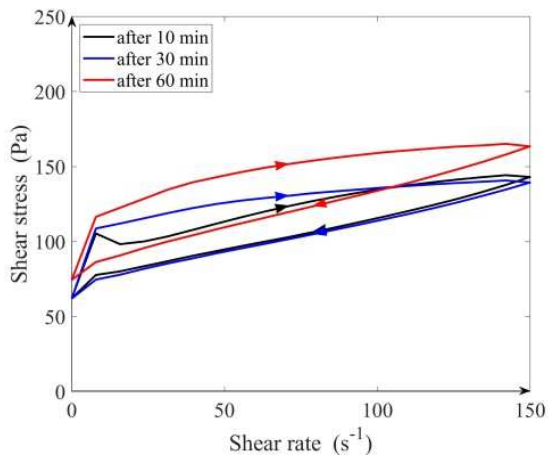

Fig. 8. Flow curves of cement paste $\mathrm{CEM} \mathrm{I}+0.5 \% \mathrm{NP}+0.75 \%$ AWA, $\mathrm{w} / \mathrm{c}=0.4$. 


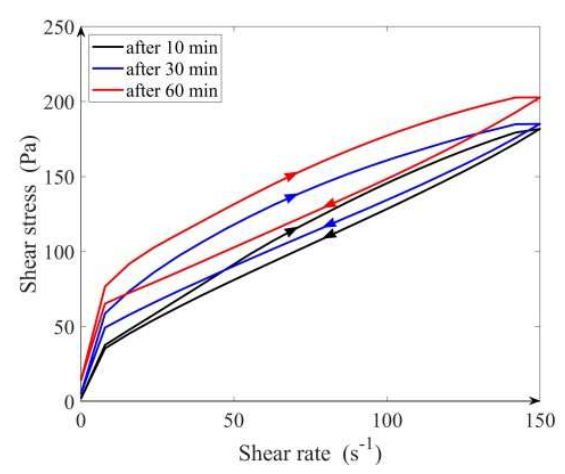

Fig. 9. Flow curves of cement paste CEM I $+0.5 \% \mathrm{NP}+0.75 \% \mathrm{AWA}+2 \% \mathrm{SP}, \mathrm{w} / \mathrm{c}=0.27$.

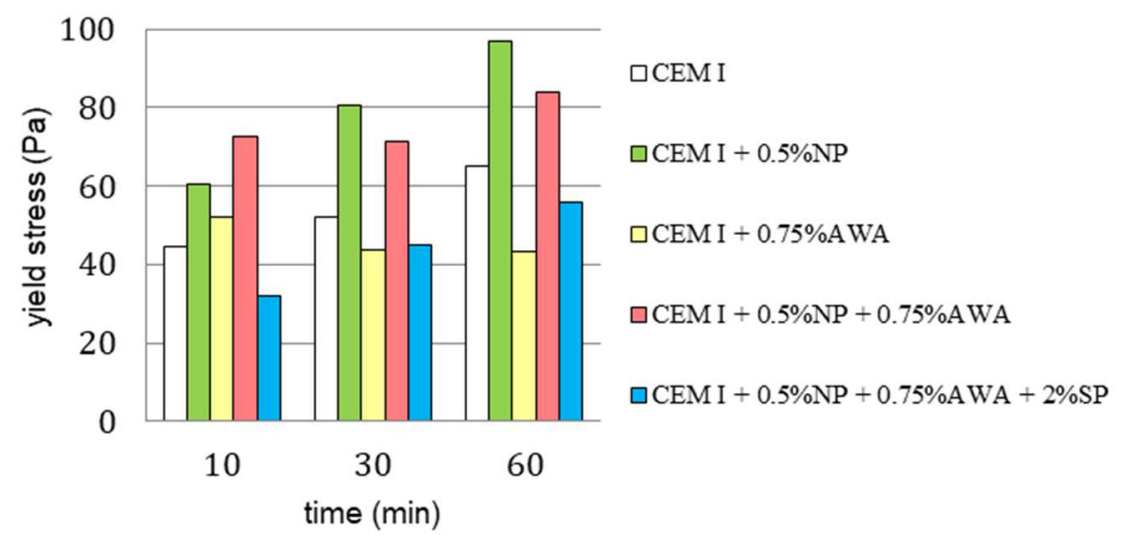

Fig. 10. Yield stress of cement pastes.

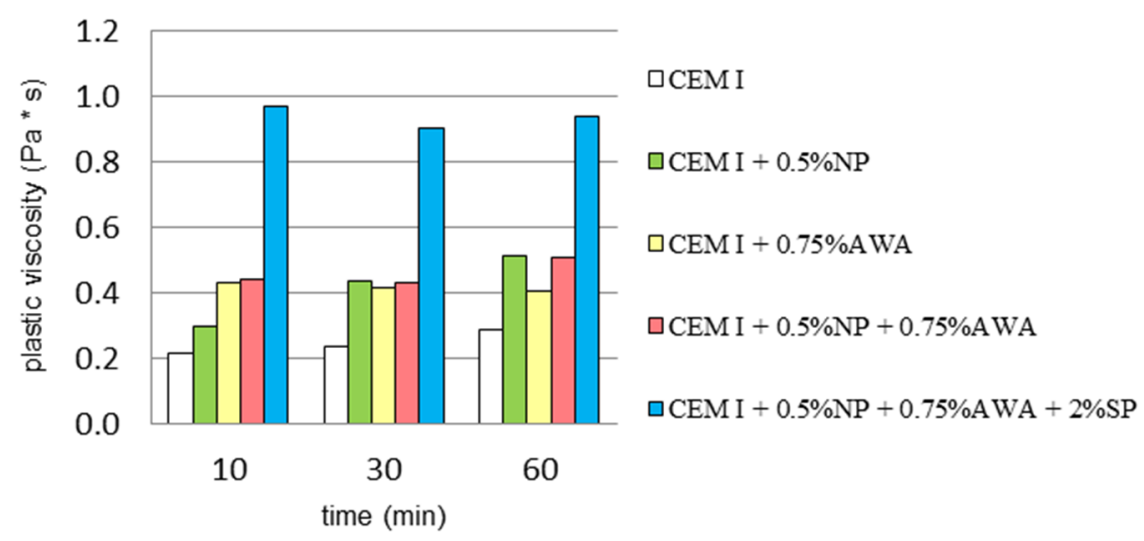

Fig. 11. Plastic viscosity of cement pastes.

The analysis of rheological parameters of cement pastes tested, presented in Fig. 10 and 11 demonstrated that $0.75 \%$ of AWA results in a significant increase of the plastic viscosity of the paste compared to the viscosity of the paste without the AWA, and the yield stress remained on a similar level within the time up to 60 minutes. Addition of a small amount of NP also caused the significant increase of the plastic viscosity and a clear growth of the yield 
stress within up to 60 minutes. Addition of both AWA and NP has the influence on the increase of the plastic viscosity, and in particular on the increase of the yield stress compared to values of these parameters for the paste with AWA. The phenomenon observed can be explained by the mechanism of AWA's action in the presence of NP [9].

The largest impact on the value of rheological parameters of cement pastes tested has the addition of $2.0 \%$ SP. In the paste with SP admixture, in order to eliminate sedimentation, it was necessary to reduce the w/c ratio from 0.4 to 0.27 . But still the paste, where AWA, NP and SP was introduced to, showed a low yield stress (Fig. 10), but a significant plastic viscosity, above $0.90 \mathrm{~Pa} \cdot \mathrm{s}$ (Fig. 11). It is caused by a dominant impact of SP on the paste rheological properties in the presence of AWA and NP admixture. The observed influence of $\mathrm{SP}$ on the value of rheological parameters is characteristic for polycarboxylate-based SP and it is used in self-compacting concrete technology.

\subsection{Setting Time}

Test results of setting time are presented in a graph (Fig. 12). Setting times were tested at the standard consistency. The paste consistency was controlled by adding a suitable amount of water. Figure 12 also shows the water demand of cements with admixture of NP, AWA and SP.

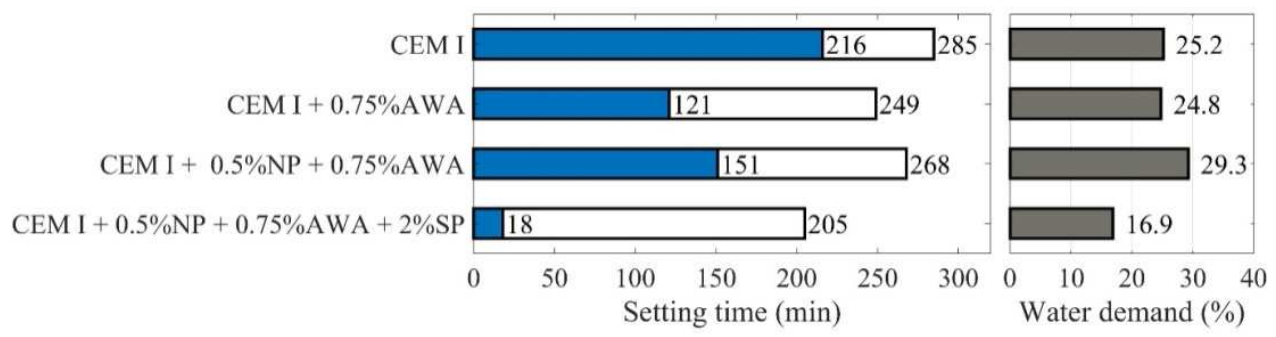

Fig. 12. Initial and final setting time and water demand of cements

The analysis of data shown in Figure 12 indicates that both AWA, as well as application of AWA and NP jointly, causes shortening of the setting time compared to the reference sample. The shortening of the setting time caused by NP is known from the literature [17]. The shortest setting time was achieved for the specimen with the addition of NP, AWA and $2.0 \%$ SP simultaneously. It results from the fact that tests were conducted at the standard consistency, which with such a large amount of SP, required significant reduction of water in the specimen (the water demand equal to 16.9\%). Taking into account the rheological properties of cement pastes with the above mentioned admixtures (Fig. 11) it can be stated that the impact of these admixtures (AWA, NP, SP) on the cement setting time is related with their effect on the paste plastic viscosity. The increase of the paste plastic viscosity causes shortening of the cement setting time.

\section{Summary}

Test results of the cement hydration heat demonstrated that the addition of AWA and SP caused the delay of the hydration process, which increased along with the quantity of the admixture in the paste, and the impact of the superplasticizer on the delay of the hydration process was revealed to the greater extent.

Combined application of AWA and SP in the cement paste causes a slight extension of the induction period and a slight shift of heat effects towards the longer time compared to the 
specimen with addition of the superplasticizer only. Addition of $\mathrm{SiO}_{2}$ particles to that arrangement causes further extension of the induction period and the shift of heat effects towards even the longer time. The observed delay of the cement hydration process due to introduction of $\mathrm{SiO}_{2}$ particles to the cement containing AWA and SP was explained by the mechanism of AWA's action.

It was proved that AWA causes the significant increase of the cement paste plastic viscosity. Whereas addition of $\mathrm{SiO}_{2}$ particles clearly increased both the plastic viscosity and the yield stress with a tendency to a large growth of those parameters over time (up to 60 minutes). Cement pastes, where $\mathrm{AWA}$ and $\mathrm{SiO}_{2}$ particles were jointly applied, showed the higher yield stress and plastic viscosity compared to values of those parameters for the paste containing only AWA. The increase of the cement paste plastic viscosity under the impact of nanoparticles in the presence of AWA can be used in the underwater concrete technology to limit the washout of the paste from the concrete mix.

It was found that the superplasticizer present in the cement paste containing AWA and $\mathrm{SiO}_{2}$ particles shaped the paste rheological properties in the greatest extent. It causes a significant water reduction of the paste, even at the lower w/c ratio and reduction of the yield stress, with simultaneous increase of the plastic viscosity.

It was demonstrated that AWA used separately and together with NP caused shortening of the cement setting time compared to the reference sample, and that influence was mostly revealed in shortening of the initial setting time.

\section{References}

1. X. Y. Sam, D. E. Berner, B. C. Gerwick, US Army Corps of Engineers, USA (1999)

2. S. Nagataki, H. Seki, N. Otsuki, Concrete Library of JSCE, 19 (1992)

3. T. Kawai, Marine Concrete (International Congress on Polymers in Concrete, Brighton, England, 1987)

4. V. S. Ramachandran, Concrete Admixtures Handbook (Noyes Publications, Park Ridge, N.J. 528-533, 1984)

5. N. Van Chanh, The 3rd ACF International Conference ACF/VCA (Ho Chi Minh, Vietnam, 2008)

6. S. Grzeszczyk, B. Skaliński, 4th International Conference Non-traditional Cement and Concrete (Eds: Bilek and Kersner, Brno, 2011)

7. A. McLeish, Underwater concreting and repair (Halsted Press, New York, USA, 1994)

8. S. J. Kojouri, A. A. Abang Ali, N. Farzadnia, Adv. Mat. Res. 1133, p. 491-495 (2016)

9. S. Grzeszczyk, K. Jurowski, K. Bosowska, M. Grzymek, Constr. Build. Mater. 203, 670678 (2019)

10. M. H. Zhang, K. Sisomphon, T. S. Ng, and D. J. Sun, Constr. Build. Mater. 24 (9) 17001707 (2010).

11. M. Saric-Coric, K. H. Khayat, A. Tagnit-Hamou, Cem. Concr. Res. 33 (12), 1999-2008 (2003)

12. S. Grzeszczyk, K. Jurowski, J. Kowalska, Cement Lime Concrete 6, 515-524 (2019)

13. A. Kaleta, S. Grzeszczyk, Procedia Eng. 108, 568-574 (2015)

14. M. A. Sikandr, Constr. Build. Mater. 245, 1-10 (2020)

15. W. Kiernożycki, J. Błyszko, Cement Lime Concrete 6, 432-447 (2019)

16. W. Nocuń-Wczelik, B. Trybalska, Cement Lime Concrete 6, 284-289 (2007) 
17. L. Senff, J. A. Labrincha, V. M. Ferreira, D. Hotza, and W. L. Repette, Constr. Build. Mater. 23 (7), p. $2487-2491$ (2009) 